\title{
Student Leadership Perceptions in South Africa and the United States
}

\author{
Laura M. Getz ${ }^{1,2}$ \& Michael M. Roy ${ }^{2,3}$ \\ ${ }^{1}$ Department of Psychology, University of Virginia, Charlottesville, VA, USA \\ ${ }^{2}$ Department of Psychology, Elizabethtown College, Elizabethtown, PA, USA \\ ${ }^{3}$ Music Department Research Associate, North-West University, Potchefstroom, South Africa \\ Correspondence: Laura Getz, Department of Psychology, University of Virginia, Charlottesville, VA, USA. Tel: \\ 1-434-982-4751. E-mail: lmg5ep@virginia.edu
}

Received: January 28, 2013

Accepted: March 19, 2013 Online Published: May 14, 2013

doi:10.5539/ijps.v5n2p1

URL: http://dx.doi.org/10.5539/ijps.v5n2p1

\begin{abstract}
The present study examined high school and college students' perceptions of leadership traits necessary for outstanding leaders to possess in South Africa and the United States. Students $(N=124)$ indicated traits that both inhibited and facilitated outstanding leadership using modified Project GLOBE (House et al., 2004, Culture, leadership, and organizations: The GLOBE study of 62 societies, SAGE Publications) questionnaires. Results showed that: 1) Overall valence of trait dimensions remained constant across cultures and developmental stages; 2) South African students rated traits less strongly than American students overall, showing a less distinct definition of outstanding leadership; 3) College students' ratings of positive versus negative leadership traits were more differentiated than their high school counterparts' ratings; 4) The ratings of students in this study mirrored those of business people from Project GLOBE, although college students tended to have an even more distinct definition of what makes a good leader. Overall, our findings highlight the importance of considering cultural and developmental contexts when studying leadership traits.
\end{abstract}

Keywords: adolescents, leadership perceptions, outstanding leadership, Project GLOBE, South Africa, United States

\section{Introduction}

\subsection{Leadership Challenges}

According to former South African President F. W. de Klerk, one of the main dilemmas in leadership today is the ability to manage diversity effectively (personal communication, April 8, 2008); this is especially true in a large, multicultural country such as South Africa. Booysen and van Wyk (2007) contend that diversity management and communication skills are of fundamental importance for leaders as well as followers in South Africa's diverse workforce. A number of studies indicate that a lack of leadership contributes to many problems in South Africa, including violence (Seedat et al., 2009) and the HIV/AIDS epidemic (Chersich and Rees, 2008; Chopra et al., 2009; Coovadia et al., 2009; Wood \& Webb, 2008). In contrast, successful leadership was one of the key factors in achievements such as improved responsiveness in hospitals (Puone et al., 2008) and resiliency in schools (Christie \& Potterton, 1999; Davidoff \& Lazarus, 1999; Davidoff et al., 1999).

Given the importance of leadership in South Africa to address social issues, we examined the attitudes of high school and college students, who are the country's future leaders and followers (Note 1). There has been a call to expand leadership development training not only to the businesses of South Africa, but also to schools and universities (Coates et al., 2007). South Africa is currently in a transitional phase; while past leadership research has focused on White males, equality programs mean that more women and people of color are now in leadership positions (Booysen \& van Wyk, 2007). Madi (1995) adds that researchers should be aware that the average South African is 15 years old and Black, and it is their values and perceptions that will shape tomorrow's workforce. The present study therefore examined the perception of outstanding leadership traits among Black and South Asian students in South Africa.

In order to contextualize students' perceptions, we compared them to beliefs held by high school and college students in the United States. Given that there are multiple types and definitions of leadership (Yukl, 1981), the impact of culture on leadership development is not fully understood; it is not apparent whether traits important in 
defining leaders are universal or more culturally determined (Elenkov \& Manev, 2005; House, Hanges et al., 2004; Zagorsek et al., 2004).

We chose to compare South African students to American students because of differences in the education systems in the two countries. Within the school context, the values of a society are fostered through an emphasis on developing the characteristics and abilities that are thought to enable children's future success as citizens and workers (Wentzel \& Looney, 2007). Research shows that American students learn a particular definition of leaders as "heroes" (someone acting alone to bring about significant, positive change) from an early age (Hoppe \& Bhagat, 2007), and are thus likely to have a fairly narrow understanding of leadership. In contrast, as South African schools have experienced a dramatic cultural shift in the years since Apartheid (Department of Education, 1999), schools feature a mix of Eurocentric/Western and Afrocentric cultural norms. While Western approaches to leadership have proven to be effective in improving work performance in South Africa (Booysen \& Beaty, 1997), Bolden and Kirk (2009) argue that an Afrocentric view of leadership, with an emphasis on dialogue and shared understandings, can enhance a sense of community (Avolio, 1995; Mbigi, 1999). Therefore, it may be that Black and South Asian students from South Africa, in comparison to American students, are less likely to rate any specific style of leadership as being either very important or not very important. A number of different styles might be more equally endorsed.

In addition to cultural implications, it is not known how perceptions of leadership change over the course of the lifespan. Past studies show that "emerging adulthood" (Arnett, 2004) is a period of rapid maturation and identity conflict that may lead to changes in beliefs and personality (Erikson, 1964; Roberts et al., 2001; Roberts et al., 2003). In fact, Roberts et al. (2006) note that "personality traits change more often in young adulthood [ages 18-22] than any other period of the life course" (p. 14). This period of young adulthood is also the time when individuals enter college, and it has been found that during college, "individuals become more independent, explore new opportunities, and reconsider their values, goals, and beliefs about themselves" (Robins et al., 2005, p. 489). As a result, students tend to become less narcissistic (Roberts et al., 2010) and more open to experience (Robins et al., 2001) during their college years. To understand differences in traits seen as important for successful leaders during this period of emerging adulthood, we assessed leadership perceptions of both high school and upper-level college students. It may be that a shift in values and greater independence causes ideas about what might make an effective leader to also shift during this period, with college students more likely to endorse participative and collaborative leadership styles than would high school students.

\subsection{Present Study}

The purpose of the current study was twofold: to assess cultural differences in leadership perceptions between South African and American students, and to assess developmental differences in leadership perceptions between high school and college students compared to adult business leaders. The present study extends previous research to high school and college students of Black and South Asian descent in South Africa and White high school and college students in the United States. Students were given a modified questionnaire from the Global Leadership and Organization Behavior Effectiveness (GLOBE) Project (GLOBE Foundation, 2006) in order to evaluate their perceptions of leadership traits. In Project GLOBE, researchers examined the impact of culture on leadership and organizational practices by assessing the perceptions of adult business leaders in 62 cultures. House et al. (2004) found six Culturally-Endorsed Leadership Theory (CLT) dimensions that were viewed in a similar manner universally-Charismatic/Value-Based, Team-Oriented, Participative, Humane-Oriented, Autonomous, and Self-Protective leadership. Because Project GLOBE included adults in South Africa and the United States, we were able to compare current students' views about leadership with those of adult business leaders.

\subsection{Hypotheses}

First, given that American students are more likely to be taught a narrow definition of leadership (Hoppe \& Bhagat, 2007), whereas South African students likely endorse both Western and Afrocentric approaches to leadership (Avolio, 1995; Mbigi, 1999), we hypothesized that South African students may endorse a larger range of traits as necessary for a successful leader to possess than do American students. Although the valence of leadership traits may be similar between the two cultures, we predicted that American students would rate a small number of traits with high importance while South African students would rate a larger number of traits as being at least moderately important to leaders.

Findings from the GLOBE study support this hypothesis, demonstrating the existence of multiple models of leadership within South Africa, as Black and White South Africans reported different understandings of leadership (House et al., 2004). For example, White South Africans were more likely to endorse charismatic and 
participative over autonomous and self-protective leadership styles than were Black South Africans. Further, White South Africans were more similar to participants from the United States in their ratings of important leadership traits than they were to Black South Africans. Similarly, we predicted that Black and South Asian students from South Africa, in comparison to American students, would be less likely to rate any specific style of leadership as being either very important or not very important; a number of different styles might be more equally endorsed.

Second, we hypothesized that South African and American college students would likely rate helpful traits higher and harmful leadership traits lower than do high school students. Involvement with formal schooling shapes the ways in which students interact with one another, attend to events occurring in their environment, and attempt to solve problems (Mejia-Arauz et al., 2007; Rogoff \& Lave, 1984; Rogoff \& Toma, 1997). Additionally, emerging adulthood is a period of personal transformation as individuals become more independent and explore new opportunities during their college years (Robins et al., 2005). The re-evaluation of personal beliefs and goals that happens during the college years (Roberts et al., 2001, 2003), as well as increased first-hand interaction with leaders, was predicted to cause college students to embrace more interactive and collaborative leadership styles than their high school counterparts. This would lead college students to possess a more narrow definition of successful leadership overall, whereas high school students may a have a less clear understanding of traits necessary for successful leaders, rating many traits as moderately important.

Finally, we hypothesized that current high school and college students would rate traits with a similar valence as adults included in Project GLOBE. Further, we predicted that our participants' ratings would be more moderate overall than the GLOBE adults, continuing a developmental trend. However, it may also be that the importance placed on traits may be different between students and adults, especially in South Africa, as a function of historical timing (Note 2). Specifically, as Apartheid has now ended more than 15 years ago, and because Black South Africans have been steadily gaining more leadership opportunities in the past decade, perceptions about the traits needed to be a successful leader may have shifted during this time, emphasizing a broader range of necessary traits now than in the past.

Overall, the current study expands upon past research by examining students' attitudes about necessary leadership traits for outstanding leaders to possess. We were interested in comparing students from South Africa and the United States to determine the impact of cultural differences on leadership styles as the world becomes more of a "global village" (Zagorsek et al., 2004). We were also interested in possible developmental differences in beliefs about leadership during the period of "emerging adulthood" (Arnett, 2004) to better understand the role of age and education on leadership perceptions. We believe that the current study highlights the importance of considering cultural and developmental contexts when studying leadership traits.

\section{Method}

\subsection{Participants}

Participants included 32 high school students (11 males; average age 17.8) and 30 Education majors (15 males; average age 24) from the KwaZulu-Natal province in South Africa who were Black or of South Asian descent. Although these ethnic groups have obvious differences, the two groups are often categorized together as non-Whites. Both groups have been historically oppressed and thus share a similar place in South African society. In fact, a recent issue of South African Journal of Psychology focused on how the "vestiges of the old order continue to intrude on the daily lived experiences of ordinary South African citizens in the post-apartheid period" (Bowman et al., 2010, p. 365). Therefore, we felt it was acceptable to combine them for the present study.

To establish a comparison, 29 high school students (15 males; average age 18) and 33 Education majors (4 males; average age 20.5) from Pennsylvania also participated in this study; all participants from the United States were White. Education majors were chosen by means of convenience sampling (Note 3) in South Africa; therefore, we used Education majors in the United States as well. However, the leadership views of education majors are particularly relevant to the goals of this study because these students will become leaders in their classrooms (Davidoff \& Lazarus, 1999), and therefore, will model leadership skills for the next generation of students.

\subsection{Measure}

We utilized a modified version of the two Project GLOBE leadership sections, which each included 56 characteristics or behavioral descriptions (GLOBE Foundation, 2006). Answering on a 7-point Likert-type scale (1-3 = inhibits, $4=$ no effect, 5-7 = contributes to), participants rated how important they believed each characteristic to be in describing an outstanding leader. The wording was changed on several items to help students relate to the characteristics outside of a business/organizational context; namely, subordinates was 
changed to others and the words "in your organization or industry" were left out of the instructions (Hanges \& Dickson, 2004, p. 127). Additionally, as English is not the first language for many of the South African participants, the researchers went through each definition with a South African professor to ensure the meanings would likely be understood without translating the surveys (Note 4). The revised version was given to all students so that all participants received identical surveys (Note 5).

\subsection{Procedure}

Prior to participation, students filled out a consent form (Note 6). The GLOBE surveys were administered to participants in a classroom setting; they were asked to write their gender and age on the first page, but no other identifying factors were present on the surveys. Participants were told that they could ask the researchers to further explain traits that were unclear; however, no one asked for clarification. All participants completed the survey in about 20 minutes though they were given unlimited time.

\subsection{Data Analysis}

As in Project GLOBE, 75 of the 112 questionnaire items were combined into six CLT dimensions (see House et al., 2004, Table 8.4), ensuring the structural equivalence between our sample and the GLOBE sample (van de Vijver \& Leung, 2011). We then computed Cronbach's alpha scores for each CLT dimension with the South African and United States samples. Although not as high as Project GLOBE (where all internal consistency ratings exceeded 0.85), most alphas reached an acceptable level (see Table 1).

Table 1. Cronbach's alphas for CLT dimensions by country

\begin{tabular}{lllll}
\hline & Attribute items & First-order factors & S. Af. alpha & U.S. alpha \\
\hline Team-Oriented Leadership & 20 & 5 & 0.85 & 0.67 \\
Charismatic Leadership & 22 & 6 & 0.84 & 0.57 \\
Participative Leadership & 8 & 2 & 0.63 & 0.75 \\
Humane-Oriented Leadership & 5 & 2 & 0.66 & 0.48 \\
Autonomous Leadership & 4 & 1 & 0.15 & 0.52 \\
Self-Protective Leadership & 16 & 5 & 0.61 & 0.57 \\
\hline
\end{tabular}

Notes. The 75 attribute items were taken from the GLOBE questionnaire behaviors/characteristics. These attribute items were combined to make 21 first-order factors. The first-order factor items were used to calculate South Africa and United States alpha scores and were combined to make scores for the 6 CLT dimensions (which were subsequently used in all Results section analyses).

\section{Results}

Two (South Africa vs. United States) by two (high school vs. college) ANOVAs were performed for each of the six CLT dimensions. Descriptive statistics for our samples and Project GLOBE (House et al., 2004) are reported in Table 3. To address the threat of alpha inflation, we computed an omnibus MANOVA considering the six CLT dimensions jointly; Wilks' Lambda for both country, $F(6,104)=5.70, p<.001, \eta_{\mathrm{p}}{ }^{2}=.25$, and school, $F(6,104)$ $=3.76, p=.002, \eta_{\mathrm{p}}{ }^{2}=.18$, was significant, indicating that there was an overall difference between South Africa and the United States and between high school and college students on the CLT dimensions (the overall interaction was not significant, $\left.F(6,104)=.33, p=.92, \eta_{\mathrm{p}}{ }^{2}=.02\right)$.

\subsection{Cultural Differences}

To compare cultural differences, we divided the CLT dimensions into two categories. Four dimensions (hereafter: Top 4) were rated as facilitating outstanding leadership in both countries (i.e., had an overall average rating greater than 4): Charismatic/Value-Based, Team-Oriented, Participative, and Humane-Oriented leadership. Two dimensions (hereafter: Bottom 2) were rated as inhibiting outstanding leadership (i.e., had an overall average rating less than 4): Autonomous and Self-Protective leadership.

Although the overall valence of the six CLT dimensions was the same for students in South Africa and the United States, the relative importance placed on the dimensions differed significantly for five of the six dimensions across cultures (see Table 3). As predicted, South African students rated a larger number of traits as contributing somewhat to outstanding leadership, whereas American students showed more of a distinction in 
their rating of contributing and inhibiting traits. South African students rated three of the Top 4 dimensions significantly lower than did American students, seeing these traits as contributing less to outstanding leadership: Team-Oriented leadership, $F(1,115)=4.02$ (Note 7), $p=.047, \eta_{\mathrm{p}}{ }^{2}=.03$, Charismatic/Value-Based leadership, $F(1,115)=4.43, p=.037, \eta_{\mathrm{p}}{ }^{2}=.04$, and Participative leadership, $F(1,119)=17.88, p<.001, \eta_{\mathrm{p}}{ }^{2}=.13$. In contrast, South Africans students viewed the Bottom 2 dimensions as less harmful for successful leaders, rating them significantly higher than did American students: Self-Protective leadership, $F(1,115)=17.39, p<.001, \eta_{\mathrm{p}}{ }^{2}$ $=.13$ and Autonomous leadership, $F(1,117)=11.51, p=.001, \eta_{\mathrm{p}}{ }^{2}=.09$. There was no significant difference in Humane-Oriented leadership across cultures, $F(1,118)=.55, p=.46, \eta_{\mathrm{p}}{ }^{2}=.005$.

\subsection{Developmental Differences}

Although the valence of the six CLT dimensions remained the same, the relative importance of three CLT dimensions showed significant differences between high school and college students collapsed across culture (see Table 3). College students rated two of the Top 4 dimensions, Team-Oriented leadership, $F(1,115)=6.70, p$ $=.011, \eta_{\mathrm{p}}{ }^{2}=.06$, and Participative leadership, $F(1,119)=7.40, p=.008, \eta_{\mathrm{p}}{ }^{2}=.06$, as being more beneficial to outstanding leaders than did high school students. In contrast, college students rated the Bottom 2 dimension of Autonomous leadership as more harmful to leaders than did high school students, $F(1,117)=21.92, p<.001, \eta_{\mathrm{p}}{ }^{2}$ $=.16$. Charismatic/Value-Based leadership, $F(1,115)=2.82, p=.10, \eta_{\mathrm{p}}{ }^{2}=.02$, Humane-Oriented leadership, $F(1,118)=1.96, p=.16, \eta_{\mathrm{p}}{ }^{2}=.02$, and Self-Protective leadership, $F(1,115)=1.17, p=.28, \eta_{\mathrm{p}}{ }^{2}=.01$, showed no significant differences between high school and college students, although trends were all in the predicted direction. Additionally, there were no significant interactions between culture and age.

\subsection{Comparison to Project GLOBE}

The pattern of results for our participants was similar to the GLOBE study: there were no differences in the valence of the Top 4 and Bottom 2 in either country. However, contrary to our expectations, there was a tendency for our participants to assign greater leadership contribution to the Top 4 dimensions and greater leadership detriment to the Bottom 2 dimensions than the GLOBE participants, with some of the ratings from the GLOBE sample falling outside of the $95 \%$ confidence intervals of the present results (see Table 3). South African college students rated the Top 4 dimensions as more important than did the Black GLOBE Sample. South African high school students had higher ratings for Team-Oriented and Charismatic leadership than the Black GLOBE sample. However, these ratings did not differ significantly from the White South African sample's ratings. American college students rated Team-Oriented and Participative Leadership as more important and the Bottom 2 dimensions as more detrimental than did the United States GLOBE sample. American high school students had higher ratings for Team-Oriented and lower ratings for Self-Protective leadership than the GLOBE sample.

Table 2. Means $(M)$ and $95 \%$ confidence intervals $(C I)$ for CLT dimensions

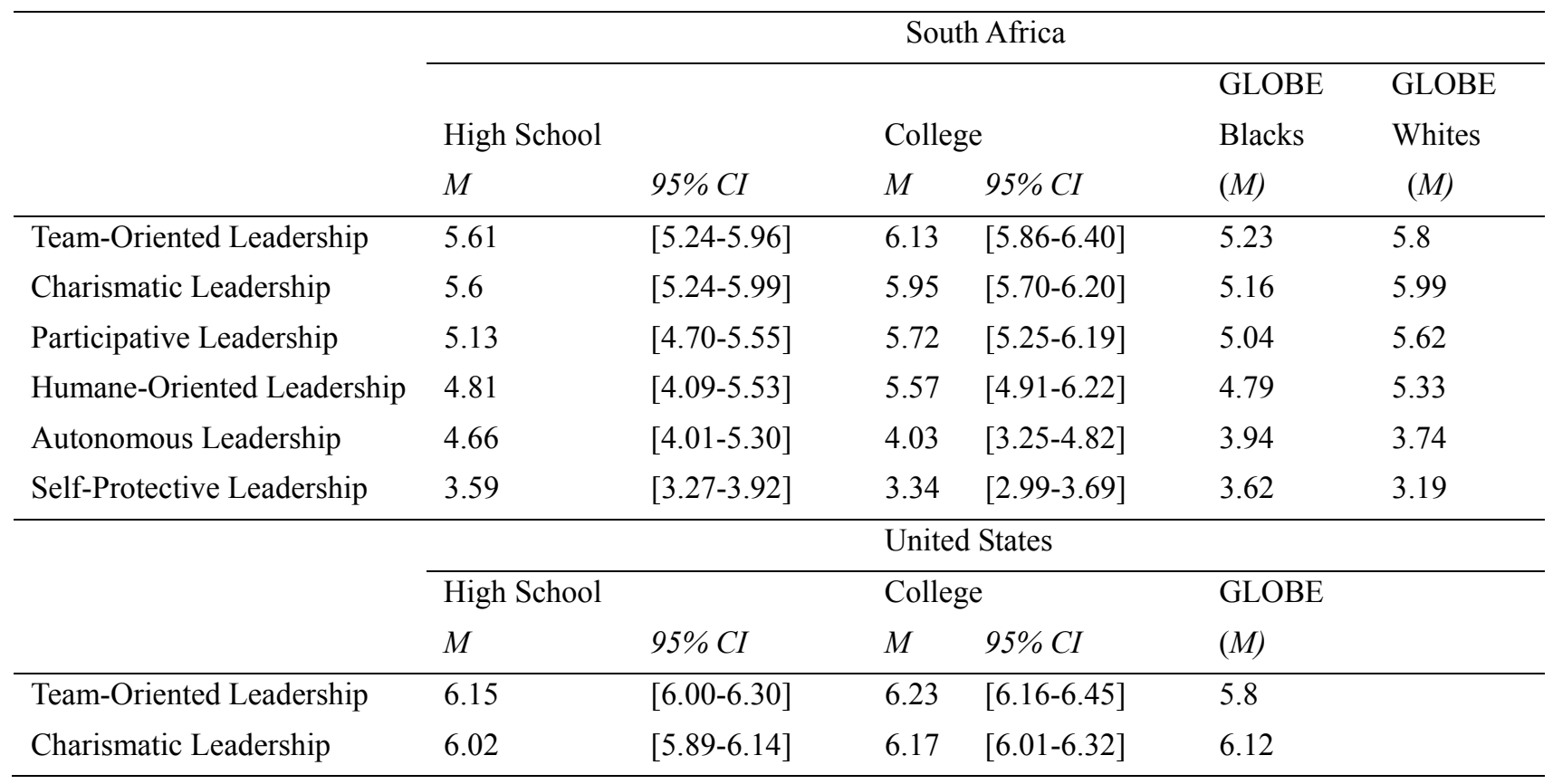




\begin{tabular}{llllll}
\hline Participative Leadership & 6.08 & {$[5.76-6.40]$} & 6.28 & {$[6.05-6.52]$} & 5.93 \\
Humane-Oriented Leadership & 5.24 & {$[4.80-5.68]$} & 5.42 & {$[5.01-5.84]$} & 5.21 \\
Autonomous Leadership & 4.07 & {$[3.37-4.77]$} & 2.67 & {$[2.14-3.20]$} & 3.75 \\
Self-Protective Leadership & 2.87 & {$[2.68-3.07]$} & 2.8 & {$[2.59-3.01]$} & 3.15 \\
\hline
\end{tabular}

\section{Discussion}

In the present study, we examined leadership perceptions of South African high school and college students. To contextualize their views, we compared their perceptions to those of students in the United States. We also compared perceptions between high school and college students in relation to adult business leaders from both countries to determine a developmental progression of leadership perceptions.

Before discussing cultural and developmental differences, it is important to emphasize the commonalities in views of leadership worldwide; people from many countries rate the six CLT dimensions with a similar valence in defining outstanding leaders (House et al., 2004). In our sample of students from the United States and South Africa, Charismatic/Value-Based, Team-Oriented, Participative, and Humane-Oriented leadership were seen as traits contributing to outstanding leadership, while Autonomous and Self-Protective leadership were viewed as detracting from outstanding leadership. However, despite the global appeal of these traits, notable differences were still found between South African and American students as well as between high school and college students. Scores from the six CLT traits in South Africa implied a less firm distinction between helpful and harmful leadership traits; three of the Top 4 dimensions were rated significantly lower (less beneficial) and the Bottom 2 dimensions were rated significantly higher (less harmful) in South Africa than in the United States.

This cultural variation in leadership ratings may be due to differences in the understanding of leadership is in South Africa and the United States. The literature on leadership in the United States points to a particular type of hero leader as effective (Hoppe \& Bhagat, 2007); students may have used this single image to inform their ratings of an outstanding leader. In contrast, students from South Africa may have incorporated Western and Afrocentric views of leadership into their definition of a successful leader (Avolio, 1995; Bolden \& Kirk, 2009; Booysen \& Beaty, 1997; Mbigi, 1999; Nsamenang, 2011; van Eeden et al., 2008), causing a broader definition overall. Another possible reason for the cultural differences could be that overall conditions in each country reinforce different concepts of leadership. Following the framework proposed by Maslow (1954), it is possible that because South Africans are more likely to deal with safety and survival issues such as poverty, crime, and AIDS on a daily basis, less attention may be given to other social or self-actualization issues, such as the attributes that make a good leader.

Second, the present study found that college students' perceptions of outstanding leadership were more distinct than those of high school students. Two of the Top 4 dimensions were rated higher by college than high school students, while Autonomous leadership (one of the Bottom 2) was rated significantly lower among college students than among high school students. College students may have a stronger sense of what traits are beneficial versus harmful for successful leaders, while high school students rate traits more equally.

This shift may be due to the period of personal transformation that comes during the college years (Erikson, 1964; Robins et al., 2005). Re-evaluating personal beliefs and values, and becoming more open to new experiences (Robins et al., 2001), may lead college students to value Team-Oriented and Participative leadership more and Autonomous leadership less. In general, attending college may provide students with more personal examples of leadership upon which to base their ratings, leading them to have more distinctive view of helpful and harmful leadership practices. However, it is also true that, on average, college attendees, as compared to their peers who do not attend college, are more academically successful in secondary school and come from families with higher socioeconomic status (Arnett, 2004). Differences between high school and college students' leadership perceptions may consequently relate to these demographic characteristics rather than to changes in experience. Either way, it is clear that the college-educated population in South Africa and the United States - those who will most likely be future leaders - show a similar pattern of distinctly defined leadership perceptions.

Third, high school and college students' scores in the present study were similar to the adult sample included in Project GLOBE (House et al., 2004); the valence of the Top 4 and Bottom 2 dimensions was constant, indicating that traits viewed as necessary for successful leadership remain relatively stable throughout the lifespan. However, our participants, especially the college students, tended to place higher importance on contributing 
traits and lower importance on inhibitory traits than did the adult sample. It may be that college students are particularly focused on a Team-Oriented and Participative approach to leadership that diminishes with age and experience. Alternatively, differences might be specific to our sample of college students; Education majors may be more likely to ascribe to a specific brand of leadership that may not generalize to a business context.

Several limitations of the present study should be addressed. First, in order to eliminate the possibility of between-subject variability and better establish a developmental pattern, future research should include longitudinal, rather than cross-sectional, measures of leadership perceptions. Second, the current study used a rather small sample from each country that differed in both gender and age constitutions, raising the possibility that the differences we found were due to sampling-related issues. However, the fact that the results closely replicated those from a much larger sample of Project GLOBE and the omnibus MANOVA test was significant (addressing the concern of alpha-inflation) helps to validate the present results. Further, while there were age differences in our two college samples, we were not precisely interested in age, but rather experience differences between high school and college students. Regardless, future research would be well served by having age more closely matched across cultural contexts. Third, although steps were taken to make the survey equally accessible to all students, it is possible that South African and American students did not have the same understanding of the characteristics. South African students' classes are taught in English starting in third grade, yet English is still a second language for many of the South African students included in this study. Therefore, in the future, it may be advisable to administer surveys in the students' native language. Finally, inevitable cultural differences, such as socioeconomic status, government structure, crime rates, etc., could not be sufficiently controlled in this study. As with any cross-cultural research (see van de Vijver \& Leung, 2011), these differences should be remembered when evaluating the results and implications of the study.

Overall, the leadership traits seen to facilitate and inhibit outstanding leadership were similar in both cultures. South African students showed less of a distinction between positive and negative traits in defining successful leaders, giving lower ratings to positive traits and higher ratings to negative traits. American students, on the other hand, assigned particularly high importance to positive traits, possibly following a narrow view of leaders as heroes. Moreover, college students across both cultures had more distinctly defined ideas about what constitutes an outstanding leader, with positive traits increasing and negative traits decreasing in importance. Ratings were similar to adults surveyed in Project GLOBE, although college students rated several traits as being more important than did adults. The results demonstrate the importance of considering culture and life-stage in the study of perceived outstanding leadership practices.

\section{References}

Arnett, J. J. (2004). Emerging adulthood: The winding road from the late teens to the early twenties. New York: Oxford University Press.

Avolio, B. J. (1995). Integrating transformational leadership and Afro-centric management. Human Resource Management, 11, 17-21.

Bolden, R., \& Kirk, P. (2009). African leadership: Surfacing new understandings through leadership development. International Journal of Cross-Cultural Management, 9, 69-86. http://dx.doi.org/10.1177/1470595808101156

Booysen, A. E., \& van Wyk, M. W. (2007). Culture and leadership in South Africa. In J. S. Chhokar, F. C. Brodbeck, \& R. J. House (Eds.), Culture and leadership across the world: The GLOBE book of in-depth studies of 25 societies (pp. 433-474). Mahwah, NJ: Lawrence Erlbaum Associates.

Booysen, A. E., \& Beaty, D. T. (1997). Linking transformation and change leadership in South Africa: A review of principles and practices. $S B L$ Research Review, 1, 9-18.

Bowman, B., Duncan, N., \& Sonn, C. (2010). Editorial: Towards a psychology of South Africa's histories-living with and through the apartheid archive. South African Journal of Psychology, 40, 365-369.

Chersich, M. F., \& Rees, H. V. (2008). Vulnerability of women in southern Africa to infection with HIV: Biological determinants and priority health sector interventions. AIDS, 22, S27-S40. http://dx.doi.org/10.1097/01.aids.0000341775.94123.75

Chopra, M., Lawn, J. E., Sanders, D., Barron, P., Abdool Karim, S. S., Bradshaw, D., ... Coovadia, H. (2009). Achieving the health millennium development goals for South Africa: Challenges and priorities. The Lancet, 374, 1023-1031. http://dx.doi.org/10.1016/S0140-6736(09)61122-3

Christie, P., \& Potterton, M. (1999). Resilient schools: A South African study. In J. Gultig, T. Ndhlovu, \& C. 
Bertram (Eds.), Creating people-centred schools: School organization and change in South Africa (pp. 93-99). Capetown: Oxford University Press Southern Africa.

Coates, T. J., Fiamma, A., Szekeres, G., Dworkin, S., Remien, R. H., Hanson, B. W., \& Rudatsikira, J. (2007). Business' role in exercising leadership, promoting equity, embracing accountability, and developing partnerships. AIDS, 21, S3-S9. http://dx.doi.org/10.1097/01.aids.0000279688.23535.04

Coovadia, H., Jewkes, R. Barron, P., Sanders, D., \& McIntyre, D. (2009). The health and health system of South Africa: Historical roots of current public health challenges. The Lancet, 374, 817-834. http://dx.doi.org/10.1016/S0140-6736(09)60951-X

Davidoff, S., Kaplan, A., \& Lazarus, S. (1999). Organizational development: An argument for South African schools. In J. Gultig, T. Ndhlovu, \& C. Bertram (Eds.), Creating people-centred schools: School organization and change in South Africa (pp. 100-109). Capetown: Oxford University Press Southern Africa.

Davidoff, S., \& Lazarus, S. (1999). Leadership and management in building 'learning' schools. In J. Gultig, T. Ndhlovu, and C. Bertram (Eds.), Creating people-centred schools: School organization and change in South Africa (pp. 64-73). Capetown: Oxford University Press Southern Africa.

Department of Education. (1999). Changing management to manage change: A new plan for South African schools. In J. Gultig, T. Ndhlovu, \& C. Bertram (Eds.), Creating people-centred schools: School organization and change in South Africa (pp. 3-8). Capetown: Oxford University Press Southern Africa.

Erikson, E. (1964). Childhood and society (2nd ed.). Oxford, W. W. Norton.

Elenkov, D. S., \& Manev, I. M. (2005). Top management leadership and influence on innovation: The role of socio-cultural context. Journal of Management, 31, 381-402. http://dx.doi.org/10.1177/0149206304272151

GLOBE Foundation. (2006). Research survey: GLOBE project (form alpha). Available at: http://www.bsos.umd.edu/psyc/hanges/index_files/GLOBE_Phase_2_Alpha_Questionnaire.pdf (accessed 4 June 2012).

Hanges, P. J., \& Dickson, M. W. (2004). The development and validation of the GLOBE culture and leadership scales. In I. R. J. House, P. J. Hanges, M. Javidan, P. W. Dorfman, \& V. Gupta (Eds.), Leadership, culture, and organizations: The GLOBE study of 62 societies (pp. 121-151). Thousand Oaks, CA: SAGE.

Hoppe, M. H., \& Bhagat, R. S. (2007). Leadership in the United States of America: The leader a cultural hero. In J. S. Chhokar, F. C. Brodbeck, \& R. J. House (Eds.), Culture and leadership across the world: The GLOBE book of in-depth studies of 25 societies (pp. 475-535). Mahwah, NJ: Lawrence Erlbaum Associates.

House, R. J., Hanges, P., Javidan, M., Dorfman, P., \& Gupta, V. (Eds.). (2004). Culture, leadership, and organizations: The GLOBE study of 62 societies. Thousand Oaks, CA: SAGE.

Madi, P. (1995). Moving the centre. People Dynamics, 13, 12-16.

Maslow, A. H. (1954). Motivation and personality. New York: Harper.

Mbigi, L. (1999). The spirit of African management. In J. Gultig, T. Ndhlovu, \& C. Bertram (Eds.), Creating people-centred schools: School organization and change in South Africa (pp. 39-47). Capetown: Oxford University Press Southern Africa.

Mejía-Arauz, R., Rogoff, B. Dexter, A., \& Najafi, B. (2007). Cultural variation in children's social organization. Child Development, 78, 1001-1014. http://dx.doi.org/10.1111/j.1467-8624.2007.01046.x

Nsamenang, A. B. (2011). The culturalization of developmental trajectories: A perspective on African childhoods and adolescences. In L. A. Jensen (Ed.), Bridging cultural and developmental approaches to psychology: New syntheses in theory, research, and policy (pp. 235-254). New York: Oxford University Press.

Puone, T., Cuming K., Sanders, D., \& Ashworth, A. (2008). Why do some hospitals achieve better care of severely malnourished children than others? Five-year follow-up of rural hospitals in Eastern Cape, South Africa. Health Policy and Planning, 23, 428-437. http://dx.doi.org/10.1093/heapol/czn036

Roberts, B. W., Caspi, A., \& Moffitt, T. (2001). The kids are alright: Growth and stability in personality development from adolescence to adulthood. Journal of Personality and Social Psychology, 81, 670-683. http://dx.doi.org/10.1037/0022-3514.81.4.670

Roberts, B. W., Edmonds, G., \& Grijalva, E. (2010). It is developmental me, not generation me: Developmental changes are more important than generational changes in narcissism-commentary on Trzesniewski and 
Donnellan (2010). Perspectives on Psychological Science, 5, 97-102. http://dx.doi.org/10.1177/1745691609357019

Roberts, B. W., Robins, R. W., Trzesniewski, K. H., \& Caspi, A. (2003). Personality trait development in adulthood. In J. T. Mortimerand, \& M. J. Shanahan (Eds.), Handbook of the life course (pp. 579-595). New York: Plenum.

Robins, R. W., Fraley, R. C., Roberts, B. W., \& Trzesniewski, K. H. (2001). A longitudinal study of personality in young adulthood. Journal of Personality, 69, 617-640. http://dx.doi.org/10.1111/1467-6494.694157

Robins, R. W., Noftle, E. E., Trzesniewski, K. H., \& Roberts, B. W. (2005). Do people know how their personality has changed? Correlates of perceived and actual personality change in young adulthood. Journal of Personality, 73, 489-522. http://dx.doi.org/10.1111/j.1467-6494.2005.00317.x

Roberts, B. W., Walton, K. E., \& Viechtbauer, W. (2006). Patterns of mean-level change in personality traits across the life course: A meta-analysis of longitudinal studies. Psychological Bulletin, 132, 1-25. http://dx.doi.org/10.1037/0033-2909.132.1.1

Rogoff, B., \& Lave. J. (Eds.). (1984). Everyday cognition: Its development in social context. Cambridge: Harvard University Press.

Rogoff, B., \& Toma, C. (1997). Shared thinking: Community and institutional variations. Discourse Processes, 23, 471-497. http://dx.doi.org/10.1080/01638539709545000

Seedat, M., Van Niekerk, A., Jewkes, R., Suffla, S., \& Ratele, K. (2009). Violence and injuries in South Africa: Prioritising an agenda for prevention. The Lancet, 374, 1011-1022. http://dx.doi.org/10.1016/S0140-6736(09)60948-X

van Eeden, R., Cilliers, F., \& van Deventer, V. (2008). Leadership styles and associated personality traits: Support for a conceptualisation of transactional and transformational leadership. South African Journal of Psychology, 38, 253-267.

van de Vijver, F. J. R., \& Leung, K. (2011). Equivalence and bias: A review of concepts, models, and data analytic procedures. In D. Matsumoto, \& F. J. R. van de Vijver (Eds.), Cross-cultural research methods in psychology, Culture and psychology (pp. 17-45). New York: Cambridge University Press.

Wentzel, K. R., \& Looney, L. (2007). Socialization in school settings. In J. E. Grusec \& P. D. Hastings (Eds.), Handbook of socialization theory and research (pp. 382-403). New York: Guilford Press.

Wood, L., \& Webb, P. (2008). The perceptions and responses of South African school principals regarding HIV and AIDS in their schools. Vulnerable Children and Youth Studies, 3, 143-149. http://dx.doi.org/10.1080/17450120701867520

Yukl, G. A. (1981). Leadership in organizations. Englewood Cliffs, NJ, Prentice Hall.

Zagorsek, H., Jaklic, M., \& Stough, S. J. (2004). Comparing leadership practices between the United States, Nigeria, and Slovenia: Does culture matter? Cross Cultural Management, 11, 16-34. http://dx.doi.org/10.1108/13527600410797774

Zhu, W., Avolio, B. J., \& Walumbwa, F. O. (2009). Moderating role characteristics with transformational leadership and follower work engagement. Group and Organization Management, 34, 590-619. http://dx.doi.org/10.1177/1059601108331242

\section{Notes}

Note 1. Followers' attitudes about what makes a good leader appear to have an important part in determining a leader's effectiveness; a study of South African industries found that more positive attitudes in followers led to higher work engagement and increased effectiveness of leaders (Zhu, Avolio, and Walumbwa, 2009).

Note 2. Data from Project GLOBE were collected between 1994 and 1997, shortly after the end of Apartheid in South Africa.

Note 3. Convenience sampling in South Africa included students of our colleague Praveen Jugmohan, Professor of Education at University of Kwa-Zulu Natal. We thank him for his help in recruiting students for this project. Participants in both countries volunteered to complete this survey, and did not receive any extra credit or payment for their participation.

Note 4. Thanks to Karendra Devroop, University of South Africa, Pretoria, for his help with the surveys. 
Note 5. Because we made very few modifications to the original Project GLOBE leadership questionnaires (i.e., only made the language more simple and in reference to a school environment rather than business setting), we did not feel it was necessary to perform a validity test on our modified questionnaires.

Note 6. With several other collaborators, the authors established an instrumental band program at a public high school in South Africa. Although some high school participants were under age 18, parental consent was not necessary because school administrators gave permission for their students to complete a number of non-invasive psychological surveys throughout the week of our music intervention. High school students in the US were chosen from a nearby high school; all students selected were over 18 so that parental consent would not be required.

Note 7. Degrees of freedom differ by CLT trait because of incomplete data from several participants. 